\title{
Letramento crítico e ensino de espanhol como língua estrangeira: questões teórico-metodológicas no contexto dos Institutos Federais (IFs)
}

DOI: http://dx.doi.org/10.21165/el.v48i2.2292

\section{Larissa Cristina Arruda de Oliveira Benedini'}

\section{Resumo}

O letramento crítico tem sido apontado nos documentos que orientam a educação brasileira de nível médio como uma perspectiva de ensino de língua estrangeira. A formação do leitor crítico também tem sido um critério de seleção das obras aprovadas pelo Programa Nacional do Livro Didático (PNLD). Nesse contexto, são nossos objetivos problematizar o conceito de letramento e leitor crítico que emerge dos documentos e dos livros didáticos, assim como a concepção de leitor crítico e letramento crítico dos professores de espanhol dos IFs. Para isso, aplicamos um questionário com vistas a obter dados sobre a concepção de leitor crítico e letramento críticos dos docentes, a fim de analisar se eles se apropriam das concepções expostas nos documentos e nos livros didáticos em suas práticas de ensino. Os resultados alcançados com as análises apontam a necessidade de maior esclarecimento quanto ao conceito de letramento crítico entre os docentes.

Palavras-chave: letramento crítico; leitor crítico; ensino de espanhol.

1 Instituto Federal de São Paulo (IFSP), Catanduva, São Paulo, Brasil; larissabenedini@gmail.com; https://orcid.org/0000-0002-3876-8926 


\title{
Critical literacy and teaching of Spanish as a foreign language: theoretical and methodological questions in the context of the Federal Institutes (IFs)
}

\begin{abstract}
Critical literacy has been pointed out in documents that guide Brazilian middle-level education as a foreign language teaching perspective. The formation of the critical reader has also been a criterion for selecting the works approved by the National Textbook Program (PNLD). In this context, our objectives are to problematize the concept of literacy and critical reader that emerges from the documents and textbooks, as well as the conception of critical reader and critical literacy of the Spanish teachers of the IFs. For this purpose, we applied a questionnaire to obtain data about critical reader conception and critical teacher literacy, in order to analyze if they appropriate the concepts outlined in the documents and textbooks in their teaching practices. The results obtained with the analyses point to the need for greater clarification regarding the concept of critical literacy among teachers.
\end{abstract}

Keywords: critical literacy; critical reader; Spanish teaching.

\section{Introdução e Objetivos}

No Brasil, vêm sendo desenvolvidas, nas últimas décadas, várias propostas curriculares e alternativas metodológicas no âmbito escolar que visam desenvolver atividades que promovam o letramento. Baptista (2010, p. 120) afırma que: "Letrar não equivale simplesmente a ensinar a ler e escrever, pressupõe criar condições para que os sujeitos possam se inserir, de maneira mais participativa e crítica, na sociedade da qual fazem parte".

Nesse sentido, Monte Mór (2015, p. 39) destaca a relevância da crítica nessa perspectiva de ensino: "nos recentes estudos sobre letramento, a questão da crítica se renova ao ser abordada por uma perspectiva que a relaciona à linguagem como prática social". A autora ainda lembra que o letramento crítico, visto atualmente com uma proposta renovada para o ensino de linguagens, "inicia-se por rever o trabalho de leitura desenvolvido nas escolas e evolui para se disseminar como um projeto educacional" (MONTE MÓR, 2015, p. 42).

Essa perspectiva, no campo do ensino, visa desenvolver o espírito crítico e preparar os alunos para compreender discursos de diversas mídias e culturas e envolvê-los na construção dos sentidos. As Orientações Curriculares para o Ensino Médio (2006) afirmam explicitamente que compete à escola formar leitores críticos e propõem que essa formação ocorra por meio de um projeto de letramento que trabalhe a linguagem (em língua materna e em línguas estrangeiras) desenvolvendo os modos culturais de ver, descrever, explicar. No que concerne à leitura, contempla pedagogicamente suas 
várias modalidades: a visual (mídia, cinema), a informática (digital), a multicultural e a crítica (presente em todas as modalidades). Esse documento destaca que o ensino de línguas deve "[...] desenvolver um leitor como aquele que entende que aquilo que lê é uma representação textual, como aquele que, diante do que lê, assume uma posição ou relação epistemológica no que concerne a valores, ideologias, discursos, visão de mundo". (BRASIL, 2006, p. 98-99).

Concordamos com Cassany e Castellá (2010) que a orientação sociocultural da leitura e da escrita (ou letramento) sugere que ler e escrever não são processos cognitivos ou atos de decodificação, mas tarefas sociais, práticas culturais enraizadas historicamente em uma comunidade de falantes. Por isso, a concepção de letramento crítico que defendemos aqui está alinhada a uma prática de ensino-aprendizagem ou perspectiva de ensino questionadora imbuída em questões sociais, políticas e ideológicas, voltada para uma crítica problematizadora dentro da sala de aula, ou seja, uma prática de ensino que prevê o agenciamento crítico dos alunos e sua formação cidadã.

Consideramos para isso as discussões teóricas sobre o conceito de letramento crítico (CASSANY, 2006; CASSANY; CASTELLÁ, 2010; MONTE MÓR, 2015; DUBOC, 2012; BAPTISTA, 2010) para o campo do ensino de línguas estrangeiras, analisamos a proposta das coleções aprovadas no PNLD 2015 e procuramos problematizar as concepções sobre letramento e leitor crítico dos professores.

Com relação aos materiais didáticos disponíveis para o trabalho em sala de aula na rede pública, no ensino médio, no Guia do PNLD de 2015, por exemplo, um dos critérios de avaliação (e exclusão) de obras para o componente curricular Língua Estrangeira Moderna (espanhol e inglês) foi considerar se os livros didáticos "permitem, fundamentalmente, a formação de um leitor crítico, capaz de ir além da decodificação de textos" (BRASIL, 2015, p. 9).

No atual contexto educacional, portanto, a importância de formar leitores críticos, capazes de avaliar os discursos, contextualizar os sentidos e posicionar-se criticamente diante das situações, em língua materna ou em língua estrangeira, apresenta-se como relevante, o que justifica a finalidade deste trabalho que discute as concepções de letramento crítico e de que forma elas se materializam nos documentos que orientam o ensino de línguas.

Neste trabalho, apresentamos resultados iniciais de uma pesquisa de doutorado que discute a noção de letramento e leitor crítico nos principais documentos para o ensino de Língua Estrangeira: os Parâmetros Curriculares Nacionais do Ensino Médio (PCNEM) de 2000, as Orientações Educacionais Complementares aos Parâmetros Curriculares Nacionais (PCN+EM) de 2002, as Orientações Curriculares para o Ensino Médio (OCEM) de 2006 
Ressaltamos que todos esses documentos foram elaborados por instâncias do Ministério da Educação (MEC) em colaboração com outras instituições educacionais e, segundo recomendam, devem ser usados na escola, tanto para a construção do projeto de ensino, quanto para a formação e atuação dos professores. Assim, além de servirem para a elaboração dos currículos escolares, para a formação inicial e continuada dos professores e para a condução das aulas, os documentos configuram as orientações de esferas públicas para o trabalho realizado na educação básica de nível médio.

São objetivos deste estudo compreender como essas concepções de letramento e leitor crítico aparecem nos documentos que orientam o ensino de línguas no país e de que forma são apropriadas por um grupo de professores de espanhol dos Institutos Federais (IFs).

\section{Materiais e Métodos}

Para o desenvolvimento deste estudo, nos baseamos em uma perspectiva qualitativa, cuja natureza teórica busca fundamentar o conceito de letramento crítico no campo da Linguística Aplicada. A revisão bibliográfica a partir dos estudos sobre letramento crítico citados nos forneceu os subsídios necessários para estruturação, obtenção e análise dos dados principalmente para a reflexão sobre as concepções de leitura e letramento crítico.

Depois, procedemos à leitura dos documentos que orientam o ensino de línguas estrangeiras no Brasil, a fim de compreender a concepção de letramento e leitor crítico presente nesses documentos. Então, elaboramos um questionário on-line para a obtenção de dados acerca das concepções sobre letramento crítico e leitor crítico dos professores de espanhol dos Institutos Federais de Educação, Ciência e Tecnologia (IFs) do Brasil.

O questionário elaborado possui um total de trinta e nove perguntas, sendo a maioria das respostas de múltipla escolha ou respostas dissertativas curtas. Contamos com a participação de trinta e um professores de espanhol da Rede Federal, sendo 44,8\% dos respondentes professores do IFSP (Instituto Federal de São Paulo), o que corresponde a quatorze profissionais; $51,6 \%$ de outros Institutos Federais, o que corresponde a dezesseis profissionais, e um $(3,2 \%)$ participante de um Colégio de Aplicação. Esse questionário circulou nas redes sociais e e-mails entre os meses de junho e setembro de 2018. Os dados aqui discutidos provêm das respostas desse questionário que também solicitou dados pessoais e outras informações sobre a formação dos professores participantes da pesquisa. ${ }^{2}$

2 Todos os participantes estão cientes do uso de suas respostas ao questionário para fins de pesquisa. O questionário completo com todas as respostas analisadas faz parte da tese de doutorado "Letramento crítico e ensino de espanhol: questões teóricas e práticas no contexto dos Institutos Federais (IFs)" em desenvolvimento. 


\section{Resultados parciais e discussão}

Os Parâmetros Curriculares Nacionais para o Ensino Médio (BRASIL, 2000) foram os primeiros documentos publicados que orientam o ensino de língua estrangeira no ensino médio em âmbito nacional. Esses documentos são resultado de um trabalho que envolveu especialista e educadores de todo país para redigir uma ferramenta que orientasse a organização curricular do ensino médio e auxiliasse os docentes em relação a suas práticas em sala de aula.

No que se refere ao ensino de língua estrangeira no ensino médio, os PCNEM (2000) defendem que o ensino de uma língua "não visa apenas ao domínio técnico, mas principalmente à competência e desempenho, ao saber usar as linguagens em diferentes situações ou contextos, considerando inclusive os interlocutores ou públicos" (BRASIL, 2000, p. 92). Dessa forma podemos afirmar que os PCNEM (BRASIL, 2000, p. 26, grifo nosso) priorizam o ensino comunicativo, pois torna-se:

[...] fundamental conferir ao ensino escolar de Línguas Estrangeiras
um caráter que, além de capacitar o aluno a compreender e a
produzir enunciados corretos no novo idioma, propicie ao aprendiz
a possibilidade de atingir um nível de competência linguística capaz
de permitir-lhe acesso a informações de vários tipos, ao mesmo
tempo em que contribua para sua formação geral enquanto cidadão.

Destacamos o desenvolvimento da competência linguística para comunicação como um dos grandes objetivos do ensino de línguas estrangeiras no ensino médio, de acordo com esse documento, pois "entende-se a comunicação como ferramenta imprescindível no mundo moderno, com vistas à formação profissional, acadêmica ou pessoal, deve ser a grande meta do ensino de Línguas Estrangeiras Modernas no Ensino Médio" (BRASIL, 2000, p. 31, grifo nosso). Portanto, observamos que nos PCNEM (2000) a língua estrangeira "assume a função intrínseca que, durante muito tempo, esteve camuflada: a de serem veículos fundamentais na comunicação entre os homens" (BRASIL, 2000, p. 26, grifo nosso).

Esse documento parece se distanciar da concepção de língua estrangeira moderna apontada pelo letramento crítico, especialmente quando se afasta de uma noção discursiva de linguagem como prática social e a coloca numa perspectiva mais próxima de noções funcionalistas, alinhando seu posicionamento a uma noção de comunicação em língua estrangeira para fins utilitários, deixando de lado a preocupação com a formação de leitores críticos que constroem significados por meio do estudo das línguas.

Já os PCN+ (2002) retomam as discussões sobre competências, no entanto, enfatizam somente o ensino de língua inglesa e dão maior relevância para a habilidade leitora. 
Nesse sentido, na parte destinada às competências abrangentes a serem trabalhadas em língua estrangeira, no subitem que se refere às estratégias para a ação, evidenciase a importância de "desenvolver o ensino de língua estrangeira por meio da leitura e interpretação de textos variados" (BRASIL, 2002, p. 108) e reforçar-se que "é essencial o desenvolvimento de técnicas de leitura que obrigatoriamente envolvam atividades de pré-leitura" (BRASIL, 2002, p. 111). Além disso, há uma seção intitulada "O texto como ponto de partida".

Portanto, é notória nesse documento a defesa do ensino baseado na leitura. Embora haja referência às outras habilidades linguísticas, a compreensão e a interpretação textual são habilidades dominantes. 0 documento ainda traz as estratégias de leitura que considera fundamentais em língua estrangeira moderna no ensino médio:

[...] é essencial o desenvolvimento de técnicas de leitura que obrigatoriamente envolvam atividades de pré-leitura e de preparação para a compreensão propriamente dita: guessing, exploração oral prévia do assunto e dos temas, levando sempre em conta o conhecimento anterior do aluno. Técnicas como skimming ${ }^{3}$ e scanning ${ }^{4}$ do texto, levantamento de palavras-chave e pesquisa de vocabulário reforçam o aprendizado autônomo e significativo. (BRASIL, 2002, p. 109).

Embora o documento ressalte a formação do leitor ativo e não do leitor crítico, nota-se uma orientação sociocultural da leitura na sua concepção de língua: "[...] é pela língua que se organizam e se comunicam saberes dos quais os indivíduos devem se apropriar no âmbito social e cultural - para gerar significados e integrar-se no mundo de forma crítica" (BRASIL, 2002, p. 98, grifo nosso).

Há também uma preocupação com a construção de uma identidade cultural do indivíduo frente à cultura do outro, o que demonstra uma orientação sociointeracionista da linguagem nesse documento.

É importante destacar que os PCN+ ampliam as orientações propostas pelos PCNs no que tange às competências que devem ser desenvolvidas no ensino médio, além de incluir a discussão sobre o caráter profissionalizante do ensino médio, a dissonância entre as necessidades formativas dos contextos escolares e o que se escreve nos projetos políticopedagógicos pelo país, a necessidade da participação da comunidade nas decisões sobre

3 Procurar pistas no texto para inferir seu sentido geral, sem ater-se a detalhes ou a leituras prolongadas.

4 Ler o texto com maior atenção, procurando informações específicas. 
o que acontece na escola e de enfatizar a importância da interdisciplinaridade nesse nível de ensino.

Já as Orientações Curriculares para o Ensino Médio (2006, p. 69) afirmam explicitamente que: "compete à escola formar leitores críticos e propõe que essa formação ocorra por meio de um projeto de letramento, que esteja diretamente relacionado aos modos culturais de usar a linguagem e que considere leitura e escrita como práticas sociais contextualizadas". Portanto, esse documento assume a concepção de leitura e escrita como uma prática social contextualizada e:

\begin{abstract}
[...] passa-se a preferir o uso do termo letramento para se referir aos usos heterogêneos da linguagem nos quais formas de "leitura" interagem com formas de "escrita" em práticas socioculturais contextualizadas. Isso leva à superação do restrito conceito anterior de "alfabetização", pautado ainda na concepção da "escrita" como tecnologia descontextualizada e universal produtora das supostas habilidades linguísticas homogêneas de leitura e escrita. (BRASIL, 2006, p. 106).
\end{abstract}

Diante desse pressuposto teórico para o ensino de línguas, com essa percepção da heterogeneidade da linguagem, o ensino de língua estrangeira baseado somente no desenvolvimento de "quatro habilidades", com uma visão homogênea da língua, já não se sustenta mais. Sendo assim, no que se refere à concepção de linguagem, as OCEM indicam que ela deve ser entendida como "constituinte de significados, conhecimentos e valores" (BRASIL, 2006, p. 131), não sendo abordada somente como forma de expressão e comunicação.

O letramento crítico no ensino de espanhol como língua estrangeira visa, por exemplo, diminuir o preconceito que opõe o espanhol peninsular em relação às variedades hispanoamericanas, como se a primeira tivesse mais prestígio ou fosse mais "pura" do que as outras. Nesse sentido, o papel do professor de espanhol passa a ser o de articulador de muitas vozes e não aquele que irá reduzi-las a um conjunto de curiosidades léxicas desconsiderando seus valores culturais e sociais.

Embora essas concepções teóricas estejam explicitadas nas OCEM, não há indicação de um método ou abordagem que deve ser adotado, apenas a sugestão dos pressupostos teóricos que conduzam ao planejamento e elaboração de materiais didáticos. Isso traz, como consequência, uma variedade de interpretações e propostas para o ensino e aprendizagem de línguas no ensino médio. 
É importante destacar que o ensino de Espanhol no Brasil ganhou espaço para ser discutido nas OCEM após a promulgação da lei $n^{0}$ 11.161/05, conhecida como Lei do Espanhol, que dispunha sobre o ensino de língua espanhola no país como sendo de oferta obrigatória pela escola e matrícula facultativa para o aluno do ensino médio. Essa lei esteve em vigor de 2005 até 2017 quando foi revogada pela lei n 13.415 de 16 de fevereiro de 2017 (decorrente da Medida Provisória n 746 de 22 de setembro de 2016) que dispõe sobre a Reforma do Ensino Médio, alterando o caráter da oferta do espanhol pela escola de obrigatória para optativa. De acordo com a nova lei, é obrigatória a oferta de um único idioma, o inglês. O espanhol pode vir como segunda opção, se houver espaço na grade curricular. Isso representa uma afronta à democracia e ao direito de escolha da comunidade, além de ser um retrocesso para a educação, em particular para a política de plurilinguismo nas escolas de educação básica do país.

Atualmente, o que está no centro das discussões sobre políticas educacionais e linguísticas é o mais recente documento publicado pelo MEC que deverá orientar o ensino na educação básica de todo país: a Base Nacional Comum Curricular (BNCC) que, em sua versão para o Ensino Médio, foi homologada pela portaria n 1.570 publicada no DOU em 21/12/2017. Destacamos que, nesse documento, não há nenhuma referência ao ensino de língua espanhola.

O que nos chama a atenção como elemento comum ao ensino de espanhol no ensino médio integrado dos IFs é a adoção, por parte da instituição, do livro didático de espanhol fornecido à escola através do PNLD. O livro didático, embora seja um polêmico objeto cultural que recebe críticas de vários setores da sociedade, ainda é o principal instrumento usado no processo de ensino-aprendizagem. O PNLD funciona como instrumento de análise das obras didáticas produzidas pelas editoras, utilizando-se de uma lista de critérios previamente estabelecidos. Cada edição do programa seleciona diferentes coleções de livros didáticos das disciplinas escolares que comporão um Guia de Livros Didáticos. A vigência de cada edição do programa é de três anos. Neste trabalho, optamos por analisar o PNLD LEM de 2015 que permaneceu nas escolas até o fim de 2017.

No Guia de Livros Didáticos do PNLD LEM de 2015, um dos critérios de avaliação (e exclusão) de obras para o componente curricular Língua Estrangeira Moderna (inglês e espanhol) foi considerar se os livros didáticos:

[...] permitem, fundamentalmente, a formação de um leitor crítico, capaz de ir além da decodificação de textos; ofereçam acesso a situações que aprimorem a fala e a escrita, por meio da compreensão de suas condições de produção e circulação e de seus propósitos sociais. (BRASIL, 2015, p. 9). 
Nesse sentido, o edital do PNLD 2015 pautou-se em uma concepção de ensino de língua estrangeira preocupada com a formação de cidadãos engajados, portanto, em consonância com a teoria do letramento crítico, por isso: "O foco na formação do leitor crítico e a viabilização do acesso a diversas situações de uso da língua, bem como de seus propósitos sociais, foram elementos fundamentais para a constituição dos critérios de avaliação adotados" (BRASIL, 2015, p. 7).

Somente em 2009, as línguas estrangeiras modernas (inglês e espanhol) foram incluídas no PNLD. Em 2011, os livros de língua estrangeira foram adquiridos pelo governo federal e chegaram às mãos dos alunos do ensino médio pela primeira vez em 2012. Nesse sentido, os livros de língua estrangeira para o ensino médio público são recentes no programa, embora a lei da obrigatoriedade da oferta de língua espanhola para o ensino médio tenha entrado em vigor em 2005.

O edital do PNLD estabelece um conjunto com vinte e sete critérios que devem ser considerados na avaliação da obra como eliminatórios para os componentes de língua estrangeira moderna. Entres esses critérios, há vários relacionados à formação de um leitor crítico, destacado como o principal critério do processo de seleção das obras. Afirma-se, neste edital, que o conjunto de critérios busca garantir que o livro didático favoreça a formação de "[...] um leitor crítico, capaz de ultrapassar a mera decodificação de sinais explícitos, e dar acesso a situações nas quais a fala e a escrita possam ser aprimoradas a partir da compreensão de suas condições de produção e circulação, bem como de seus propósitos sociais." (BRASIL, 2015, p. 11).

Ou seja, desde a sua apresentação, o Guia do PNLD LEM 2015 já destaca a preocupação com a formação do leitor crítico. Portanto, nota-se que uma perspectiva de ensino como letramento crítico atenderia os critérios relacionados à formação de leitores críticos estabelecidos neste edital.

No entanto, o edital do PNLD 2015 faz referência a várias concepções de leitura e abordagens teórico-metodológicas diversas em seus pressupostos que se misturam e se diluem na forma de critérios que contemplam as atividades de compreensão leitora e produção escrita. O que não deixa claro qual vertente teórica (leitura crítica ou letramento crítico $)^{5}$ fundamenta a própria concepção de leitor crítico que o edital assume. 0 edital apresenta no mínimo três concepções diferentes de leitura e escrita (psicolinguística, sócio interacionista e letramento crítico ou leitura crítica) para seu processo de seleção das obras.

5 Essa discussão sobre as diferenças entre leitura crítica e letramento crítico assim como as diferentes concepções de leitura (baseada em Cassany $(2006,2010)$ e Baptista (2010)) foi desenvolvida e aprofundada na tese. 
De acordo com o Guia do PNLD 2015 de Espanhol para o Ensino Médio, a coleção Enlaces (2015) aprovada apresenta em sua proposta didático-pedagógica uma visão sociointeracionista da língua. O trabalho fundamenta-se no texto e busca articular a apresentação dos gêneros às diferentes tipologias textuais, explorando as relações interculturais entre o Brasil e os países hispano falantes. Sobre o letramento crítico, embora não seja sua proposta didático-pedagógica, a coleção afirma colaborar para o desenvolvimento da criticidade favorecendo a reflexão do aluno: "[...] Buscamos promover no aluno a capacidade de construir seu próprio discurso e usá-lo de forma crítica e transformadora da sua realidade" (OSMAN et al., p. 8, 2013, tradução nossa). ${ }^{6}$

Já a segunda coleção aprovada, Cercania Joven (2015), apresenta uma proposta didáticopedagógica que integra as habilidades (leitura, escrita, escuta e fala) a partir do trabalho com diferentes gêneros textuais, tendo como princípios norteadores o letramento crítico e o desenvolvimento da cidadania. Os próprios autores mencionam explicitamente que o letramento crítico é um dos fundamentos teórico-metodológicos da obra, baseandose no conceito de letramento crítico defendido por Cassany (2006 apud COIMBRA et al. 2013, p. 209, tradução nossa7):

[...] O que se busca no ensino e aprendizagem das habilidades escritas (leitura e escrita) é um trabalho a partir da perspectiva do letramento crítico. Não basta ler as linhas do texto (alfabetização) ou entre as linhas (letramento). É necessário ler especialmente por trás das linhas, onde se reconhece jogos de poder e se compreender coisas não ditas que estarão no discurso.

Após uma breve descrição das obras aprovadas no PNLD LEM 2015 para o ensino de espanhol, destacamos que das duas coleções aprovadas apenas uma (Cercanía Joven) se assume como pautada nos postulados teóricos do letramento crítico. Porém, isso não significa que, ao escolher a coleção Enlaces, o professor não possa usar uma abordagem de ensinar pautada no letramento crítico, pois realizar atividades pedagógicas sob as premissas do letramento crítico depende não somente do material didático escolhido, mas, sobretudo, da atitude docente sobre o currículo, uma vez que "[...] a crítica desejada não se encontra pronta no material didático, no professor, nos alunos ou na instituição, mas sim na relação que emerge entre todas essas instâncias, cabendo ao professor

6 No original: "[...] Buscamos promover en el alumno la capacidad de construir su propio discurso y usarlo de forma crítica y transformadora de su realidad.".

7 No original: "[...] Lo que se busca en la enseñanza y aprendizaje de las habilidades escritas (lectura y escritura) es un trabajo desde la perspectiva de literacidad crítica. No basta leer las líneas del texto (alfabetización) o entre las líneas (literacidad). Es necesario leer especialmente tras las líneas, donde se reconoce juegos de poder y se comprende cosas no dichas que están en el discurso." (CASSANY, 2006 apud COIMBRA et al., 2013, p. 209). 
praticar essa atitude problematizadora nas brechas $^{8}$ de sua prática docente" (DUBOC, 2012, p. 107).

Nesse sentido, nos baseamos nas concepções de leitor crítico eletramento crítico (MONTE MÓR, 2015; CASSANY, 2006, 2010; BAPTISTA, 2010), e suas diferentes perspectivas como construto teórico para compreender e analisar as concepções de um grupo de professores de espanhol.

É um grande desafio trabalhar com concepções de língua e linguagem, letramento, leitor crítico, aprender e ensinar língua estrangeira a partir das vozes dos professores participantes da pesquisa. Contudo, escolhemos enfrentá-lo, pois consideramos fundamental a transformação da visão dos professores a respeito do seu objeto de ensino. Por isso, perguntamos no questionário: o que significa um leitor crítico em língua espanhola? Abaixo reproduzimos as respostas no quadro:

Quadro 1. Leitor crítico em língua espanhola

\begin{tabular}{|l|l|}
\hline Participantes & Respostas \\
\hline P1 & $\begin{array}{l}\text { Um leitor que sabe posicionar-se criticamente com argumentos baseados em } \\
\text { fatos concretos da realidade. (Sociocultural) }\end{array}$ \\
\hline P2 & $\begin{array}{l}\text { Domínio do idioma em nível gramatical; trabalho bem feito com gêneros } \\
\text { textuais, em consonância com o trabalho feito em língua materna; } \\
\text { conhecimento sobre diversidade cultural dos povos de língua hispânica e dos } \\
\text { demais idiomas falados em territórios hispânicos. (Linguística) }\end{array}$ \\
\hline P3 & Ele é curioso e questionador. (Sociocultural) \\
\hline P4 & $\begin{array}{l}\text { Quando o leitor se posiciona diante das informações apresentadas no texto. } \\
\text { (Sociocultural) }\end{array}$ \\
\hline P5 & $\begin{array}{l}\text { Leitor crítico é aquele que dialoga com o texto, no sentido de confrontar } \\
\text { informações fornecidas pelo texto e suas próprias concepções, visões, } \\
\text { leituras de mundo. (Sociocultural) }\end{array}$ \\
\hline P6 & $\begin{array}{l}\text { Um leitor que entende seu papel no mundo, que sabe o que é cidadania e que } \\
\text { sabe sua opinião sobre temas importantes do mundo atual. (Sociocultural) }\end{array}$ \\
\hline P7 & $\begin{array}{l}\text { Um leitor que saiba interagir nas diferentes práticas sociais de uso da } \\
\text { língua espanhola, interpelando, contrastando e avaliando o conteúdo do } \\
\text { texto a partir do que foi apresentado e do que ele tem de conhecimento. } \\
\text { (Sociocultural) }\end{array}$ \\
\hline
\end{tabular}

(continua)

8 Os conceitos de "brecha" e "atitude curricular" defendidos por Duboc (2012) são apresentados na nossa tese e utilizados nas análises. 


\begin{tabular}{|c|c|}
\hline P8 & $\begin{array}{l}\text { Um leitor capaz de reconhecer as diferenças, as diferentes culturas e os } \\
\text { povos. (Psicolinguística) }\end{array}$ \\
\hline P9 & $\begin{array}{l}\text { Significa saber posicionar-se e sentir-se instigado em ser e atuar para o } \\
\text { mundo, além de perceber muito mais do que as linhas de um texto. Significa } \\
\text { sair da literalidade da compreensão. (Sociocultural) }\end{array}$ \\
\hline P10 & $\begin{array}{l}\text { Significa ir além do letramento linguístico, conseguir emitir opiniões críticas } \\
\text { sobre o que foi lido (Psicolinguística) }\end{array}$ \\
\hline P11 & $\begin{array}{l}\text { Um leitor capaz de compreender as diferenças linguísticas existentes. } \\
\text { (Psicolinguística) }\end{array}$ \\
\hline P12 & $\begin{array}{l}\text { Aquele que consegue se inserir, refletir e expor sua visão sobre o que lhe é } \\
\text { posto. (Sociocultural) }\end{array}$ \\
\hline P13 & $\begin{array}{l}\text { Aquele que consegue interpretar corretamente e comentar de forma crítica e } \\
\text { coerente. (Linguística) }\end{array}$ \\
\hline P14 & Saber ler, decodificar e saber contextualizar. (Linguística) \\
\hline P15 & $\begin{array}{l}\text { Aquele aprendiz que consegue não apenas ler e escrever na língua-meta, mas } \\
\text { que principalmente compreende de maneira crítica aspectos gerais da língua, } \\
\text { construindo sentidos. (Psicolinguística) }\end{array}$ \\
\hline P16 & $\begin{array}{l}\text { Possuir experiência de leitura com diversos tipos de textos e exercitar uma } \\
\text { visão de mundo, de cidadania e diversidade étnico-racial e inclusão social. } \\
\text { (Sociocultural) }\end{array}$ \\
\hline P17 & $\begin{array}{l}\text { Aquele que consegue ir além da decodificação textual, ou seja, um leitor que } \\
\text { não apenas compreende o que está escrito, mas interpreta o sentido que vai } \\
\text { além do que se lê. Um leitor que consegue entender as entrelinhas do texto. } \\
\text { (Sociocultural) }\end{array}$ \\
\hline P18 & $\begin{array}{l}\text { Trata-se de um leitor que não conhece só regras gramaticais, mas que tem um } \\
\text { conhecimento cultural e reflexivo da língua-alvo. Além disso, pode desenvolver, } \\
\text { por meio da reflexão, a consciência cidadã e identitária ao contrapor com a } \\
\text { cultura na qual está imerso. (Sociocultural) }\end{array}$ \\
\hline P19 & $\begin{array}{l}\text { Um leitor crítico em língua espanhola é capaz de romper a barreira linguística e } \\
\text { entender o discurso contido no texto de forma eficaz. (Linguística) }\end{array}$ \\
\hline P20 & $\begin{array}{l}\text { Trata-se de um leitor que não conhece só regras gramaticais, mas que tem um } \\
\text { conhecimento cultural e reflexivo da língua-alvo. Além disso, pode desenvolver, } \\
\text { por meio da reflexão, a consciência cidadã e identitária ao contrapor com a } \\
\text { cultura na qual está imerso. (Sociocultural) }\end{array}$ \\
\hline P21 & Aquele que conhece as origens e repercussões do texto lido. (Linguística) \\
\hline
\end{tabular}

(continua) 


\begin{tabular}{|l|l|}
\hline P22 & Tem que ser um leitor com bagagem cultural (Psicolinguística) \\
\hline P23 & $\begin{array}{l}\text { Assim como em Língua Portuguesa, um leitor que, ao ler um texto, faça uma } \\
\text { análise pra além do texto, saindo do senso comum e construindo sentidos. } \\
\text { (Psicolinguística) }\end{array}$ \\
\hline P24 & $\begin{array}{l}\text { Que ler seja com a intenção de inferir sentidos ao texto, com olhar crítico e } \\
\text { humanístico. (Psicolinguística) }\end{array}$ \\
\hline P25 & $\begin{array}{l}\text { Ter uma visão geral da língua em estudo. } \\
\text { Um leitor crítico em língua espanhola seria aquele que, por meio da cultura } \\
\text { hispânica e espanhola, desenvolvesse práticas/habilidades discursivas de } \\
\text { produção de sentido na língua alvo. (Psicolinguística) }\end{array}$ \\
\hline P27 & \begin{tabular}{l} 
Acredito que tenha respondido abaixo. \\
\hline P28
\end{tabular} \\
$\begin{array}{l}\text { Um leitor crítico deve ter o domínio da leitura, da linguagem usada (escrita ou } \\
\text { falada), ter capacidade de reflexão no nível profundo, identificando a visão de } \\
\text { mundo dada no texto, explícita ou implicitamente. (Linguística) }\end{array}$ \\
\hline P29 & $\begin{array}{l}\text { Um leitor que consegue compreender as ideologias presentes nos textos. } \\
\text { (Sociocultural) }\end{array}$ \\
\hline P30 & $\begin{array}{l}\text { Um leitor crítico é aquele que é capaz não só de entender a superfície } \\
\text { linguística, mas também de compreender o(s) discurso(s) que atravessa(m) a } \\
\text { materialidade textual. Somente quando aquele que lê compreende não só que } \\
\text { sentidos estão fazendo eco num determinado texto, mas sim como eles são } \\
\text { produzidos sócio-historicamente é que se pode considerar haver aí um leitor } \\
\text { crítico. (Sociocultural) }\end{array}$ \\
\hline $\begin{array}{l}\text { Aquele que consegue atribuir significado ao que lê e transformar a } \\
\text { experiência em algo funcional para sua vida em sociedade. (Sociocultural) }\end{array}$ \\
\hline
\end{tabular}

Fonte: Elaboração própria.

Para analisar as concepções de leitura crítica dos docentes, elaboramos um quadro que sintetiza as principais características das concepções de leitura, tendo em vista o procedimento adotado para obtenção do significado do texto que, de acordo com Cassany (2006, 2010) e Baptista (2010), são: a linguística, a psicolinguística e a sociocultural. 
Quadro 2. As diferentes concepções de leitura

\begin{tabular}{|c|c|c|}
\hline Linguística & Psicolinguística & Sociocultural \\
\hline $\begin{array}{l}\text { ler = significado } \\
\text { semântico }\end{array}$ & $\begin{array}{l}\text { O significado do texto não está } \\
\text { nas palavras }\end{array}$ & ler é uma prática social \\
\hline $\begin{array}{l}\text { significado é estável } \\
\text { e único }\end{array}$ & $\begin{array}{l}\text { Significado a partir do } \\
\text { conhecimento prévio do leitor }\end{array}$ & $\begin{array}{l}\text { significado e } \\
\text { conhecimento prévio do } \\
\text { leitor têm uma origem } \\
\text { social. }\end{array}$ \\
\hline "verdade" do texto & Diferentes compreensões & $\begin{array}{l}\text { identificar pressupostos e } \\
\text { implicações presentes nos } \\
\text { discursos }\end{array}$ \\
\hline unidades léxicas & fazer inferências & $\begin{array}{l}\text { questionar as relações de } \\
\text { poder e representação, } \\
\text { problematizar a realidade }\end{array}$ \\
\hline $\begin{array}{l}\text { regras de } \\
\text { combinação }\end{array}$ & $\begin{array}{l}\text { construção de sentido de forma } \\
\text { interativa entre texto, leitor e } \\
\text { sentido. }\end{array}$ & refletir criticamente \\
\hline
\end{tabular}

Fonte: Elaboração própria.

Diante disso, adotar uma dessas concepções de leitura no ensino de língua estrangeira implica assumir uma perspectiva no processo de letramento crítico dos alunos especialmente relacionada às atividades de leitura e escrita, pois ler para decodificar, ler para interpretar e ler para questionar são leituras diferentes na aula de língua.

Para analisar as respostas, destacamos as palavras-chaves que estão relacionadas com as concepções expostas acima e agrupamos os participantes a partir dessas três concepções de leitura. Observamos que quinze professores (P1, P3, P4, P5, P6, P7, P9, P12, P16, P17, P18, P20, P29, P30, P31) apontaram em suas respostas características de uma concepção sociocultural da leitura; seis professores (P2, P13, P14, P19, P21, P28) colocaram elementos de uma concepção linguística de leitura nas suas respostas, conforme destacamos no quadro, e oito professores (P8, P10, P11, P15, P22, P23, P24, P26) aproximam-se de uma concepção psicolinguística de leitura em suas respostas. Apenas dois participantes (P25 e P27) não responderam e/ou não se enquadraram em nenhuma das concepções expostas. 
Diante desses dados, observamos que a maioria dos professores (quatorze) participantes da pesquisa possui uma concepção sociocultural de leitura conforme definida por Baptista (2010, p. 126):

\begin{abstract}
Essa concepção sociocultural é particularmente interessante já que nos permite considerar o desenvolvimento da capacidade de identificar pressupostos e implicações presentes nos discursos materializados nos diferentes textos. O que supõe, de certa forma, um investimento mais forte na interpretação e compreensão dos textos e discursos. Desse modo, entendemos que pode ser uma concepção de leitura acorde com a proposta do letramento crítico, já que mobiliza outros conhecimentos e habilidades do sujeito além daqueles presentes nas dimensões linguísticas e psicolinguísticas.
\end{abstract}

Essa leitura reflexiva e questionadora tem por objetivo levar o aluno a avaliar os diferentes textos com o fim de identificar e compreender que relações de poder eles comunicam de forma explícita ou implícita, bem como em que contextos são difundidos.

Perguntamos também no questionário o que os professores entendem por letramento crítico a fim de analisar suas concepções sobre essa perspectiva de ensino. Reproduzimos abaixo as respostas dos docentes para essa pergunta:

Quadro 3. Concepções sobre Letramento Crítico

\begin{tabular}{|l|l|}
\hline Participantes & Respostas \\
\hline P1 & Práticas de linguagem com ênfase crítica da realidade social e cultural. (Crítica) \\
\hline P2 & Diálogo com o mundo, relacionamento de ideias, autonomia de pesquisa. \\
\hline P3 & Aprendizagem consciente e reflexiva do idioma. \\
\hline P4 & $\begin{array}{l}\text { Espera-se que haja um posicionamento contra ou a favor do texto/autor } \\
\text { (Tradicional) }\end{array}$ \\
\hline P5 & $\begin{array}{l}\text { Letramento crítico é ler, compreender um texto para além da decodificação da } \\
\text { estrutura linguística e poder, assim, atribuir significados sociais da língua que } \\
\text { está em uso. (Crítica) }\end{array}$ \\
\hline P6 & $\begin{array}{l}\text { Nunca li nada a respeito. Quando estudei linguística aplicada, abordagem } \\
\text { comunicativa estava em voga. }\end{array}$ \\
\hline P7 & $\begin{array}{l}\text { É conseguir fazer uso da leitura e da escrita, situando seu discurso em } \\
\text { contextos socioculturais diferentes, selecionando gênero discursivo adequado } \\
\text { e repensando o texto, no sentido de saber por que, o que e para que está lendo. } \\
\text { (Crítica) }\end{array}$ \\
\hline
\end{tabular}

(continua) 


\begin{tabular}{|c|c|}
\hline P8 & $\begin{array}{l}\text { Sou da psicolinguística, estudei alfabetização por método fônico, então me } \\
\text { abstenho de opinar sobre letramento crítico por não concordar teoricamente } \\
\text { com a área. }\end{array}$ \\
\hline P9 & $\begin{array}{l}\text { Significa ter uma percepção mais apurada sobre as intencionalidades de } \\
\text { um texto, saindo e extrapolando os elementos linguísticos. Mas que consiga } \\
\text { observar as relações de poder postas nas entrelinhas de um dado discurso. } \\
\text { (Crítica) }\end{array}$ \\
\hline P10 & $\begin{array}{l}\text { É o entendimento da palavra escrita com capacidade de ir além do ato de } \\
\text { descodificar, sendo capaz de se posicionar criticamente (Tradicional) }\end{array}$ \\
\hline P11 & Entendimento do texto independente de seu gênero ou fonte (Tradicional) \\
\hline P12 & $\begin{array}{l}\text { O letramento que leva o aluno a entender e refletir sobre os textos que lhe são } \\
\text { ofertados (Interpretativa) }\end{array}$ \\
\hline P13 & $\begin{array}{l}\text { Fazer com que o aluno compreenda o texto de forma crítica e possa inferir } \\
\text { comentários acerca do tema proposto (Interpretativa) }\end{array}$ \\
\hline P14 & Leitura com boa decodificação, interpretação e reflexão (Tradicional) \\
\hline P15 & $\begin{array}{l}\text { Princípios educacionais que fazem com que os alunos possam compreender e } \\
\text { apreender sentidos, os efeitos de sentidos dos textos. (Interpretativa) }\end{array}$ \\
\hline P16 & $\begin{array}{l}\text { Entendo que é um processo de formação de leitor que tem por fim prepará-lo } \\
\text { para o desenvolvimento de habilidades de leitura, interpretação e expressão } \\
\text { oral e escrita. (Interpretativa) }\end{array}$ \\
\hline P17 & $\begin{array}{l}\text { Acredito que seja o ensino da leitura para além da decodificação do código } \\
\text { escrito, incluindo a análise e a compreensão da linguagem oral em diferentes } \\
\text { âmbitos sociais. (Interpretativa) }\end{array}$ \\
\hline P18 & $\begin{array}{l}\text { Entender o texto como cultural e responsável por promover a reflexão de seu } \\
\text { papel na sociedade e na vida. (Crítica) }\end{array}$ \\
\hline P19 & $\begin{array}{l}\text { É pensar a língua como parte de uma ideologia e identidade, essas tendo como } \\
\text { resultado de sua história, a qual traz variedades linguísticas que devem ser } \\
\text { amplamente divulgadas e valorizadas e que contêm em si os seus conflitos e } \\
\text { formas de pensar de cada nação, os que se distinguem da forma identitária } \\
\text { do brasileiro, mas que nos faz pensar culturalmente sobre essas diferenças e } \\
\text { refletir a sobre a cultura à luz do outro. (Crítica) }\end{array}$ \\
\hline P20 & $\begin{array}{l}\text { Entender o texto como cultural e responsável por promover a reflexão de seu } \\
\text { papel na sociedade e na vida. (Crítica) }\end{array}$ \\
\hline P21 & $\begin{array}{l}\text { Capacidade de refletir criticamente sobre as condições de produção do texto, } \\
\text { bem como seus possíveis desdobramentos. (Crítica) }\end{array}$ \\
\hline P22 & Uma pessoa que entende o que está estudando ou lendo. (Tradicional) \\
\hline P23 & Sem resposta \\
\hline
\end{tabular}

(continua) 


\begin{tabular}{|c|c|}
\hline P24 & $\begin{array}{l}\text { Leitura com intenção de promover mudanças nas atitudes, de forma crítica e } \\
\text { reflexiva acerca do tema em questão. (Crítica) }\end{array}$ \\
\hline P25 & Ler um texto e ser capaz de refletir e interagir com o que leu. (Interpretativa) \\
\hline P26 & $\begin{array}{l}\text { Letramento crítico é um princípio educacional que desconstrói o aprendizado } \\
\text { de línguas embasado na linguística frasal, voltando-se a uma abordagem das } \\
\text { práticas sociais, ideológicas, discursivas, isto é, o aprendente é levado a refletir } \\
\text { sobre língua e cultura em sala de aula. (Crítica) }\end{array}$ \\
\hline P27 & $\begin{array}{l}\text { Penso que seja uma proposta de pensar novas formas de escrever e ler em } \\
\text { Língua espanhola, com o desenvolvimento da consciência crítica dada/ } \\
\text { integrada à realidade social que o indivíduo está inserido. (Crítica) }\end{array}$ \\
\hline P28 & $\begin{array}{l}\text { Dentre outros aspectos, o letramento crítico refere-se à leitura e análise críticas } \\
\text { de textos, considerando linguagem, marcas de poder, de grupos sociais e de } \\
\text { práticas sociais presentes nas linhas e nas entrelinhas. (Crítica) }\end{array}$ \\
\hline P29 & $\begin{array}{l}\text { Um ato de ler comprometido com o que está por trás das linhas (CASSANY, } \\
\text { 2015). (Crítica) }\end{array}$ \\
\hline P30 & $\begin{array}{l}\text { Como dito acima, letramento crítico é o processo que leva não somente } \\
\text { à decodificação da superfície da língua, mas sim a uma compreensão da } \\
\text { discursividade que atravessa toda materialidade textual. (Interpretativa) }\end{array}$ \\
\hline P31 & $\begin{array}{l}\text { Para mim é um processo constante de aprender, reaprender, depreender através } \\
\text { da leitura. O letramento crítico, no meu ponto de vista, deveria ser o eixo estrutural } \\
\text { de todas as disciplinas. }\end{array}$ \\
\hline
\end{tabular}

Fonte: Elaboração própria.

Podemos considerar pelo menos três grandes orientações na concepção do que é ser crítico quando se fala de letramento crítico, de acordo com Cassany e Castellà (2010): a perspectiva tradicional que se baseia no domínio do código e mantém o significado que está no texto, a perspectiva interpretativa ou psicológica que é baseada nos processos cognitivos de compreensão e a perspectiva crítica que se baseia na construção social do sentido do texto e essa última pode ser dividida em sociocultural e a política.

Essas três diferentes perspectivas de letramento crítico emergem de diferentes concepções de leitura, explicitadas anteriormente. Portanto, utilizamos essas categorias de análise para agrupar e examinar as respostas dos participantes no que se refere às concepções de letramento crítico. Elaboramos um quadro comparativo baseado nas afırmações de Cassany e Castellà (2010) para expor essas diferenças: 
Quadro 4. Orientações nas concepções de Letramento Crítico

\begin{tabular}{|l|l|l|}
\hline $\begin{array}{l}\text { LC na Perspectiva } \\
\text { Tradicional }\end{array}$ & $\begin{array}{l}\text { LC na Perspectiva } \\
\text { Interpretativa }\end{array}$ & $\begin{array}{l}\text { LC na Perspectiva } \\
\text { Crítica (sociocultural/política) }\end{array}$ \\
\hline Domínio do código & Compreensão & Construção social do sentido \\
\hline Significado no texto & Conhecimento prévio & Significado emerge do contexto \\
\hline \multirow{2}{*}{ Interpretação correta } & Inferências & $\begin{array}{l}\text { Interpretações históricas e } \\
\text { locais }\end{array}$ \\
\hline \multirow{2}{*}{$\begin{array}{l}\text { Identificar intenção do } \\
\text { autor }\end{array}$} & Construção de significado & Relatividade da interpretação \\
\cline { 2 - 3 } & Processo cognitivo & $\begin{array}{l}\text { Questionar o sistema e } \\
\text { transformá-lo }\end{array}$ \\
\cline { 3 - 3 } & & Lutar contra as injustiças \\
\hline
\end{tabular}

Fonte: Elaboração própria.

Podemos notar, a partir das respostas dadas, que os participantes P2, P3, P6, P8 e P31 elaboraram respostas que não apresentam características de nenhuma das perspectivas que orientam as concepções de letramento crítico expostas acima. O participante P23 preferiu não responder.

Tendo em vista as diferentes concepções de letramento crítico expostas no quadro, observamos que treze participantes (P1, P5, P7, P9, P18, P19, P20, P24, P26, P27, P28, P29) colocaram em suas respostas elementos relacionados a uma concepção crítica de letramento. Destacamos nas respostas as palavras-chave que nos levaram a essa conclusão. De certa forma, todas essas respostas apontam para uma concepção de língua como discurso, espaço de construção de sentidos e representação dos sujeitos e do mundo, "isso significa dizer que a língua, que tem sua existência nas práticas sociais, é um espaço ideológico de construção e atribuição de sentidos" (JORDÃO, 2013, p. 73). Além disso, mostram uma orientação sociocultural da leitura e da escrita que leva o aluno a refletir criticamente sobre o lugar que ocupa na sociedade.

No entanto, outros participantes (P12, P13, P15, P16, P17, P25, P30) deram respostas mais próximas a uma concepção interpretativa de letramento crítico. Também destacamos no quadro de respostas as expressões que nos levaram a essa conclusão. De acordo com essa perspectiva interpretativa, a leitura é baseada nos processos cognitivos de compreensão. Aqui o leitor deve fazer uso do seu conhecimento prévio e de inferências no processo interpretativo e de construção de significado que, nesse caso, é considerado um processo interno, mental, cognitivo. Ou seja, a interpretação é uma atividade individual, por isso, ler criticamente seria articular uma resposta pessoal para si mesmo. 
Há participantes que demonstraram uma perspectiva tradicional de letramento crítico ( $\mathrm{P} 4$, P10, P11, P14, P22), pois verificamos que emerge de suas respostas expressões como "contra ou a favor do texto/autor", "entendimento da palavra escrita", "entendimento do texto", "boa decodificação", "entende o que está lendo". Dessa forma, ao atentar-se apenas aos significados das palavras, eles apagam as marcas ideológicas e históricas presentes na língua em busca da "verdade do texto", "da interpretação correta" e do ponto de vista do autor, o que impossibilita a produção de sentidos pelo leitor. Podemos notar que esta concepção de letramento crítico considera a língua e a leitura em uma visão tradicional, que se baseia no domínio do código e mantém o significado que está no texto. Uma vez que não consideram o social, a ideologia e a história presentes na língua escrita, que são elementos necessários para entender e produzir sentidos a partir de suas próprias experiências. O crítico, nesse caso, se confunde com um nível superior de compreensão que seria identificar a intenção do autor do texto e atingir assim a interpretação canônica. Concordamos com Baptista (2010, p. 124) que:

\footnotetext{
Diante do exposto, trabalhar a leitura e a escrita em língua espanhola, em conformidade com o letramento crítico, significa tratar no ensino dessa língua das diferentes visões difundidas nos textos (orais e escritos) e as formas pelas quais nossos alunos terão contato com elas e poderão ser levados a assimilá-las, questioná-las ou ainda problematizá-las. Assim, a língua é entendida como produtora da realidade, já que por meio dela são criados valores e ideias, de forma não transparente, neutra ou fixa. Esses valores e ideias são construídos e reconstruídos - e acrescentamos validados, naturalizados e legitimados - nos diversos e diferentes contextos comunicativos e interativos.
}

Nesse sentido, o letramento crítico pode contribuir para que os alunos construam sua própria compreensão da realidade, de si mesmos, dos outros e das relações entre os sujeitos envolvidos nas práticas sociais de linguagem. Dessa forma, procuramos analisar como as concepções sobre letramento e leitor crítico são apropriadas pelos documentos que orientam o ensino de línguas no país, pelos livros didáticos de espanhol do PNLD 2015 e como os professores de espanhol dos institutos federais se apropriam dessas concepções.

\section{Conclusões}

Os resultados alcançados com as análises evidenciaram que os conceitos de letramento e leitor crítico se apresentam de forma polissêmica e difusa nos documentos que orientam o ensino e nos livros didáticos, o que os tornam conceitos banalizados entre os docentes que os reproduzem sem aprofundamento teórico. Observamos que as OCEM e o PNLD 2015 estão em consonância quanto ao leitor em língua estrangeira que se 
pretende formar no ensino médio: um leitor crítico, embora não esteja clara a concepção de letramento crítico adotada.

Nossas análises apontam a necessidade de maior esclarecimento quanto ao conceito de letramento crítico entre os docentes participantes da pesquisa, já que alguns demonstraram desconhecimento sobre os princípios teóricos para o trabalho com essa perspectiva de ensino. Além disso, notamos que há um descompasso entre a proposta dos livros didáticos selecionados e a concepção dos docentes, o que demonstra a necessidade de avaliar a efetividade de programas como PNLD e outras políticas públicas de ensino de línguas no país.

Essa constatação implica também a necessidade de se repensar o processo de formação inicial e continuada de professores de língua espanhola de forma que as concepções teórico-metodológicas que fundamentam os documentos que orientam o ensino de línguas repercutam significativamente na formação docente para refletir na concepção e atuação dos professores em sala de aula do ensino regular.

Consideramos que a opção pelo letramento crítico enquanto prática para o ensinoaprendizagem de língua espanhola no Brasil pode ser um dos caminhos possíveis para o desenvolvimento de consciência crítica, levando os alunos a refletir sobre seu lugar e papel em uma sociedade cada vez mais complexa.

\section{REFERÊNCIAS}

BAPTISTA, L. M. T. R. Traçando caminhos: letramento, letramento crítico e ensino de espanhol. In: BARROS, C. S.; COSTA E. G. M. (ed.). Espanhol: ensino médio. Coleção explorando o ensino. Brasília: Ministério da Educação, Secretaria da Educação, 2010. p. 119-136.

BRASIL. Guia de Livros Didáticos: PNLD 2015 - Língua Estrangeira. Brasília: Ministério da Educação, Secretaria de Educação Básica, 2015. Disponível em: http://bit.ly/2JCEHBr. Acesso em: 01 jun. 2018.

BRASIL. Orientações curriculares para o ensino médio. Linguagens, códigos e suas tecnologias. Conhecimentos de Línguas Estrangeiras. Brasília: MEC, Secretaria de Educação Básica, 2006. p. 127-164. Disponível em: http://bit.ly/2xl78bN. Acesso em: 01 jun. 2018.

BRASIL. Parâmetros curriculares nacionais: Ensino Médio. Brasil, Brasília: MEC. Secretaria de Educação Básica, 2000. Disponível em: http://bit.ly/2xKelle. Acesso em: 01 jun. 2018.

CASSANY, D. Tras las líneas. Sobre la lectura contemporánea. Barcelona: Anagrama, 2006. 
CASSANY, D.; CASTELLÀ, J. Aproximación a la literacidad crítica. Perspectiva, Florianópolis, v. 28, n. 2, p. 353-374, jul./dez. 2010.

DUBOC, A. P. M. Atitude curricular: letramento crítico nas brechas da formação de professores de inglês. 2012. Tese (Doutorado em Estudos Linguísticos e Literários em Inglês) - Faculdade de Filosofia, Letras e Ciências Humanas, Universidade de São Paulo, São Paulo, 2012.

COIMBRA, L. et al. Cercanía Joven: espanhol. Rio de Janeiro: Edições SM, 2013.

MONTE MÓR, W. Crítica e letramentos críticos: reflexões preliminares. In: ROCHA, C. H.; MACIEL, R. F. (org.). Língua estrangeira e formação cidadã: por entre discursos e práticas. Coleção Novas Perspectivas em Linguística Aplicada. v. 33. 2. ed. Campinas: Pontes Editores, 2015.

OSMAN, S. et al. Enlaces. São Paulo: Macmillan, 2013. 